\title{
LAS INTERVENCIONES ANTRÓPICAS EN EL CURSO BAJO DEL Guadalete y en San Pedro durante la Edad Moderna
}

\section{ANTHROPIC INTERVENTIONS ON THE LOWER COURSE OF GuAdalete AND SAN PEDRO Rivers DURING THE MODERN AGE}

\author{
ENRIQUE PÉREZ FERNÁNDEZ \\ enpefer@hotmail.es
}

\section{Centro de Educación Permanente de Adultos ${ }^{1}$}

[RECIBIDO: 26/11/2017; ACEPTADO: 07/03/2018]

http://dx.doi.org/10.25267/Riparia.2018.v4.06

\section{RESUMEN}

El artículo documenta las obras antrópicas realizadas durante la Edad Moderna en el curso bajo del río Guadalete y en el río San Pedro, en los términos municipales de Jerez de la Frontera y El Puerto de Santa María. Después de situar espacial y cronológicamente los embarcaderos del Guadalete -La Corta, El Portal, Puerto Franco, Sidueña y El Puerto - estudiamos las tres principales obras efectuadas en ambos cursos fluviales, que originaron largos conflictos entre Jerez y El Puerto a causa de los intereses enfrentados entre una ciudad realenga y otra de régimen señorial: la excavación por Jerez de un canal que comunicó el Guadalete con el San Pedro (1648); la apertura en el Guadalete, en lugar inmediato a la ciudad de El Puerto de Santa María, del Caño del Molino (1701), y la excavación de un nuevo cauce del Guadalete desde el San Pedro (1722), el que ha llegado a nuestros días. Finalmente, anotamos los proyectos, nunca ejecutados (1766-1859), que pretendieron verter las aguas del Guadalete a su paso por El Puerto hasta el San Pedro con el fin de evitar la colmatada y peligrosa barra de su desembocadura.

1 Profesor de Historia en Centro de Educación Permanente de Adultos, Jerez de la Frontera (Cádiz).

E. Pérez Fernández, «Las intervenciones antrópicas en el curso bajo del Guadalete y en San Pedro durante la Edad Moderna », RIPARIA 4 (2018), 146-190. 
Palabras Claves: Río Guadalete, Río Salado o San Pedro, Jerez de la Frontera, El Puerto de Santa María, obras fluviales, conflictos, Edad Moderna.

\section{AbstraCt}

The article documents the anthropic works carried out during the Modern Age in the lower course of the Guadalete and San Pedro rivers, within then municipal boundaries of Jerez de la Frontera and El Puerto de Santa María. After placing the docks of the Guadalete river -La Corta, El Portal, Puerto Franco, Sidueña and El Puerto -spatially and chronologically, we study the three main works carried out on both rivers, which led to long lasting conflicts between Jerez and El Puerto due to the conflicting interests of a royal and a seigniorial city: the opening of a channel in Jerez to communicate the Guadalete with the San Pedro river (1648); the opening of Caño del Molino (1701) next to El Puerto de Santa María on the Guadalete and the excavation of a new course for the Guadalete from San Pedro river (1722) which still exists today. Finally, we list the projects, never accomplished (1766-1859), that were supposed to transfer water from the Guadalete as it flowed past El Puerto to the San Pedro river in order to avoid the abundant and dangerous sediments of its estuary.

KEY WORDS: Guadalete river, Salado or San Pedro river, Jerez de la Frontera, El Puerto de Santa María, river works, conflicts 
A comienzos de los últimos años veinte pasó por El Puerto de Santa María Francisco Cambó, entonces líder de la Liga Regionalista de Cataluña. Sus anfitriones en la ciudad lo invitaron a contemplar el Guadalete, y asomado a él preguntó '¿A dónde se va por este río?' Ante el sepulcral silencio de los presentes repitió la pregunta, y ya uno dijo 'Ahora a ninguna parte', y otro 'A la bahía'. Cambó se encogió de hombros y se retiró ${ }^{2}$. Significativa anécdota que aún en nuestros días da que pensar e invita a reflexionar, pues muy poco tiene que ver el Guadalete que vio Cambó y el que hoy es -ni siquiera en su cauce- con el río que fue.

Decía a mediados del siglo XII el geógrafo andalusí alZuhri que su agua al paso por la población de al-Qanatir (El Puerto de Santa María) "se utiliza para beber y para lavar", que vendría a decir que sus aguas fluviales corrían y desaguaban hasta el mismo mar. $^{3}$. Aquel era el Guadalete "que corre con gran brío", menciona una de las Cantigas de Santa María alfonsí ${ }^{4}$. El Guadalete del que Alfonso X, en la Carta-Puebla fundacional de la villa de Santa María del Puerto (diciembre de 1281) decía:

“...teniendo que el puerto que llaman de Santa María [...], que es entre Xerés e la çibdat de Cadis, e tiene de la una parte la Grand Mar que çerca todo el mundo e que llaman Oçeano, e el gran río de Guadalquivir, e de la otra el mar Mediterraneo e el río de Guadalete, que son dos aguas dulçes por ó vienen grandes navíos"

\footnotetext{
2 Esta anécdota la contó uno de los anfitriones, el periodista, escritor y andalucista portuense M. López MuÑoz, Las trovas del Guadalete, El Puerto, 1926, 63.

3 Al-Zuhri, Kitab al-Yu 'rafiya. Trad. D. Bramon, El mundo en el siglo XII. El tratado de alZubri, Barcelona, 1991, 157.

4 J. Montoya Martínez, "Cancionero de Santa María de El Puerto. Edición, Traducción y Notas”, Alcanate I (1998-99), 141 y 235.

5 M. GonzÁlez Jiménez "El Puerto de Santa María en tiempos de Alfonso X el Sabio”, El Puerto de Santa María, 1988, 25.
}

«Las intervenciones antrópicas en el curso bajo del Guadalete... » 
El río al que el rey Sabio concedió, en marzo de 1283, algunos privilegios para el buen desarrollo de la población:

"Por faser bien e merçed a los pobladores del Puerto de Santa María, e porque se pueble mejor el lugar, tengo por bien que todos los baxeles cargados que passaren por el río de Guadalete para yr a Xerés que se descargue y el tercio, también de vianda commo de madera o de otras cosas que ellos mester ovieren" $"$.

Y otra cantiga alfonsí cuenta que una riada del Guadalete se llevó un puente existente en El Portal (que probablemente deba de entenderse en su antigua acepción de embarcadero), cuyas maderas llegaron a Santa María del Puerto y se emplearon en los andamiajes de la iglesia-fortaleza (Castillo de San Marcos) que entonces, hacia 1268, se construía ${ }^{7}$.

Importante cuestión ésta de las riadas y grandes avenidas del Guadalete para entender la evolución del curso del río. Que aumentaron durante la llamada Pequeña Edad de Hielo que comenzó a principios del siglo XIV y en la que se sucedían períodos de intensas lluvias con otros de sequía que, junto con los aportes de ingentes cantidades de sedimentos que arrastró el río durante la intensa deforestación que sufrió la Sierra de Cádiz desde la Baja Edad Media, conllevó que el Guadalete en su curso bajo creara numerosos bajos que a su vez formaron, abriéndose paso el río entre sus propios sedimentos, meandros y tornos que a mediados del siglo XVII, coincidiendo con unos de los máximos picos de la Pequeña Edad de Hielo, dificultaban mucho la navegación.

\footnotetext{
${ }^{6}$ IBIDEM, 28.

7 Dice la cantiga: "Hizo venir una riada de agua, que pasó por el Portal / y arrastró un puente de madera, tan íntegra / como en él estuviera; nunca se vio mejor. / Y por el río Guadalete la hizo llegar, / tal como estaba, allí donde / construían la iglesia, / para que no fallasen en terminar / a tiempo la obra". AL-ZuHri, Kitab al-Yu 'rafiya, 145 y 237.
} 
Fue entonces, en 1648, cuando se realizó, por controvertida decisión del Cabildo jerezano, la primera obra antrópica que transformó el curso natural del Guadalete, abriéndose una zanja que lo unió con el Salado de Puerto Real (desde entonces también nombrado San Pedro). Además de mejorar la navegación de los barcos del comercio desde el muelle de El Portal, la vía fluvial abierta buscaba dar salida a los productos jerezanos -destacadamente el vino -a la Bahía de Cádiz por el término realengo de Puerto Real, eludiendo así los impuestos que el duque de Medinaceli, señor jurisdiccional de El Puerto de Santa María, imponía a los barcos jerezanos a su paso por la ciudad. La apertura del canal conllevó un largo litigio entre ambas poblaciones, que no fue sino la disputa entre dos ciudades -una realenga y otra de régimen señorial -con intereses económicos enfrentados. Otro tanto ocurrió con la segunda gran obra antrópica que se verificó en 1721-1722, cuando el Estado, con el beneplácito de El Puerto y el desacuerdo de Jerez, cerró el curso del San Pedro para enlazarlo al Guadalete, abriendo en las marismas un canal de cerca de 4 kilómetros (el curso que ha llegado a nuestros días), convirtiéndose desde entonces el San Pedro en un brazo de mar sólo alimentado por las mareas.

Estas dos importantes obras fluviales, al igual que otras de menor relevancia que también recogemos en este artículo, han permanecido inéditas en la historiografía hasta que fueron objeto de nuestras investigaciones. Por ello, la intención del autor es fijar por vez primera los cambios antrópicos que experimentaron ambos cursos fluviales durante la Edad Moderna en el ámbito espacial de dos ciudades que durante los siglos XVII y XVIII conocieron un notable desarrollo comercial y económico desde sus muelles fluviales. Queda fuera de nuestro alcance, por no ser materia de nuestras investigaciones, las repercusiones que en la economía tuvieron las obras realizadas, con el añadido de que aún está pendiente de estudio el comercio jerezano canalizado desde sus embarcaderos fluviales, así como el flujo de mercaderías, en 
barcos nacionales y europeos, que por ellos entraron durante la Edad Moderna.

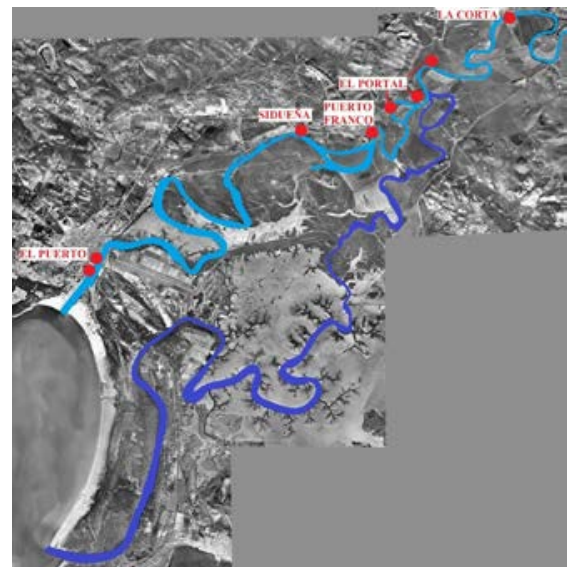

Fig. 1. Embarcaderos del Guadalete durante la Edad Moderna y curso del río San Pedro (azul) antes de su cierre parcial en 1721. Fotograma vuelo americano 1956.

\section{Los embarcaderos de la ribera del Guadalete.}

Se entiende como curso bajo del Guadalete el que principia, una vez cruzada la depresión aluvial de los Llanos de Caulina, en las inmediaciones del jerezano puente de Cartuja y abriéndose paso por terrenos de marismas desemboca a la Bahía de Cádiz por la ciudad de El Puerto de Santa María. Ocupan las marismas del Guadalete el espacio de un antiguo estuario originado, a resultas de movimientos tectónicos, al comienzo de la Era Cuaternaria (aproximadamente 1.600.000 años). La progresiva colmatación del estuario del Guadalete hasta su transformación en marismas (1.120 hectáreas) fue un proceso devenido al lento transcurrir del tiempo.

Los depósitos fluviales del Guadalete (gravas y arenas del Pleistoceno Superior, de 30000 a 25000 años) continuaron depositándose en el estuario -desde la desembocadura del río cerca del puente de Cartuja -hasta el comienzo de la transgresión 
marina post-glacial, hace 14000 años. Por entonces se produjo una considerable subida del nivel del mar que se mantendría activa hasta hace 9600 años, cuando comenzó una deceleración en el nivel al que siguió un aumento máximo en la extensión del estuario abierto, cronológicamente fijado hace 6800-6500 años. Entonces la evolución derivó a una llanura mareal, encontrándose el nivel del mar a $-12 \mathrm{~m}$ de la actual superficie de las marismas. Posteriormente, durante un corto periodo (de 6000 a 5800 años $\mathrm{BP})$, hubo una leve bajada del nivel marino provocada por el depósito de arenas fluviales y agua dulce.

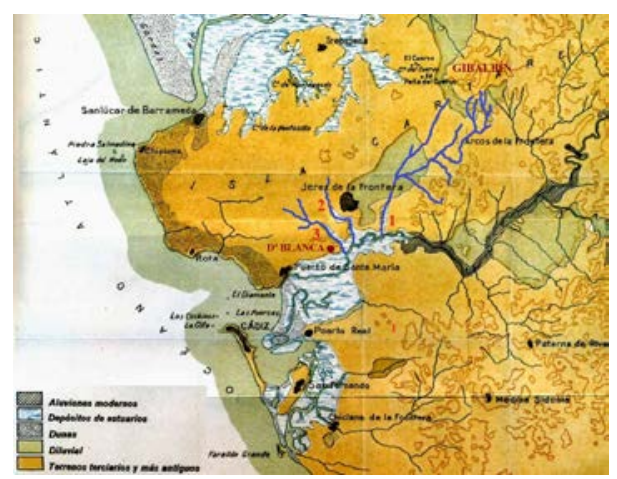

Fig. 2. Estuarios del Guadalquiviry Guadalete según J. Gavala y Laborde (1959). Grafías añadidas: Arroyos: 1-Albadalejo; 2- Guadajabaque; 3Matarrocines o del Carrillo.

El proceso continuó con la evolución del estuario a delta y una nueva subida del nivel del mar, proceso que perduró hasta hace 4500-4200 años, cuando comenzaron a surgir flechas litorales - la de Valdelagrana, frente a El Puerto de Santa María, la más activa -que conllevaron el progresivo bloqueo y colmatación del estuario y el comienzo de la formación de las marismas del Guadalete $^{8}$.

8 J. LARIo Gómez Último y presente interglacial en el área de conexión Atlántico-Mediterráneo (Sur de España). Variaciones del nivel del mar, paleoclima y paleoambientes. Tesis Doctoral

«Las intervenciones antrópicas en el curso bajo del Guadalete... » 
Es conocida que la navegabilidad en el estuario del Guadalete seguía siendo factible a fines del siglo IX antes de Cristo o comienzos del VIII, cuando colonos fenicios establecieron una población al pie de la Sierra de San Cristóbal: el yacimiento arqueológico del Castillo de Doña Blanca, el puerto de embarque de Gadir de la producción agrícola de la región. Que los barcos comerciales y pesqueros se adentraban hasta el puerto fenicio de Doña Blanca es un hecho incuestionable, pero, hoy por hoy, nos es desconocido el estado que presentaba el estuario, en qué momento se encontraba su colmatación al momento del arribo de los primeros colonos fenicios a la bahía de Cádiz. Hacia los siglos V-IV a.C. el aspecto del antiguo estuario se parecería más a un lago -como el gran lacus Ligustinus que en época romana se abría en toda la extensión del antiguo estuario del Guadalquivir -con un calado aún suficiente para navegar, pero con dificultad, abriéndose paso los barcos por diversos caños que cruzarían amplias zonas de marismas y, sobre todo, por el curso del Guadalete que pasaba al pie de la Sierra, apoyándose en la antigua orilla firme y cuyo trazado -la desaparecida 'madre vieja' del Guadalete que llamaban en la Edad Moderna - pasaba al pie de la población fenopúnica. Finalmente, en los últimos años del s. III a.C. la vieja ciudad de Doña Blanca fue abandonada una vez que perdió su carácter de puerto marítimo. Desde entonces el Guadalete modificaría su curso en tramos cada vez que sus propios sedimentos cegaran su cauce con la formación de meandros, tornos y bajos. Y también la actividad antrópica en los siglos modernos fue decisiva en las

Inédita. Universidad Complutense de Madrid, 1996, 171-190. C. J. DABRIO, J. L. GOY, J. LARIO, F. BORJA, A. GONZÁLEZ, "The Guadalete stuary during the Holocene times (Bay of Cádiz, Spain)", INQUA MBSS Subc. Newsletter 17, (1995), 19-22. C. DABRIO, J. L. GOY, C. ZAZO, "Holocene changing coastlines in the Guadalete estuary (Bay of Cádiz, Southern Spain", Reunión Monográfica sobre el cambio de la costa. Los sistemas de Rías, (1995), 45-50. F. J. Gracia, C. Alonso, M. Gallardo, F. Giles, J. Benavente, F. López AGuAyo, "Evolución eustática postflandriense en las marismas del Sur de la Bahía de Cádiz”, Geogaceta, 27, (2000), 71-74. 
transformaciones que el bajo Guadalete conocería en su recorrido.

La construcción del puente de Cartuja al comienzo de la Edad Moderna (1525- 1541) ${ }^{9}$, con sus nueve arcadas (en Fig. 3, A), provocó que el curso del Guadalete a su paso fluyera con más dificultad y colmatara su entorno; lugar donde antes existió, al decir de Joaquín Portillo, "una puente antigua, gastada del tiempo, llamada del vado de Medina"10. Enclave éste de notable importancia por ser el vado el lugar de paso de Jerez a la Bahía y a la Sierra de Cádiz y de la Bahía al Valle del Guadalquivir; y también el punto de entrada de las tropas musulmanas que repetidamente asolaron la región gaditano-xericiense desde mediados del s. XIII y el escenario donde se libraron "legendarios" enfrentamientos bélicos, de los que se hicieron eco los viejos cronistas jerezanos (sin olvidar que en sus inmediaciones fue donde probablemente se dio la batalla que cambió la Historia de España en 711) ${ }^{11}$.

Próximo al puente $(400 \mathrm{~m})$ el río recibe las aguas del arroyo Salado de Caulina, que aún en la Edad Moderna era un importante torrente que alimentaba al Guadalete, ayudando a que sus aguas corrieran con fluidez. Es el arroyo que entonces llamaban Albadalejo, "que este le entra después del paso del famoso Puente

\footnotetext{
9 R. Romero Medina y M. Romero Bejarano, “Arquitectura tardogótica en el sur del antiguo Arzobispado de Sevilla: los maestros canteros y la construcción del puente de Cartuja (1525-1541)", Boletín del Museo e Instituto Camón Ažar, 106, (2010), 251-288. En su construcción se empleó piedra de Martelilla, cantera que se abrió con tal motivo y situada próxima, en el margen izquierdo de las marismas del Guadalete.

10 J. Portillo, Noches jerezanas, o sea la bistoria y descripción de la M. N. y M. L. Ciudad de Jerez de la Frontera y su término, Jerez, 1839, 97.

11 Aunque existe una corriente historiográfica nacida a mediados del s. XIX que sostiene que la Batalla del Guadalete se libró junto a la laguna de la Janda y el río Barbate, las fuentes históricas “insisten”, como demostró Sánchez-Albornoz (1944), en que fue el wadi Lakeka = Guadalete el escenario del encuentro bélico. Siendo improbable que se librara en los inestables terrenos de las marismas del Guadalete, lo más razonable es que el escenario fuera el entorno del vado del puente de Cartuja, el lugar acostumbrado de entrada y de refriegas bélicas provocadas por los contingentes musulmanes que hasta el s. XV asolaron Jerez y su alfoz.
}

«Las intervenciones antrópicas en el curso bajo del Guadalete... » 
$y$ antes del Monasterio de Cartuja" ${ }^{12}$. Nacido al pie de la Sierra de Gibalbín -que desde el Neolítico fue un importante núcleo poblacional y de control del territorio -el curso del Albadalejo debió ser en la Antigüedad una destacada vía de comunicación de enlace con la antigua Bahía (en Fig. 2).

Después el Guadalete vira a la derecha buscando los terrenos firmes de la margen derecha del antiguo estuario, donde se alza el monasterio de la Cartuja (1478). En su humilladero, los monjes, durante sus momentos de esparcimiento contemplaban la ribera del Guadalete y, en lontananza, la bahía; al decir de fray Esteban Rallón a mediados del s. XVII:

"Está fundada esta insigne fábrica sobre el ribazo del río Leteo, hoy Guadalete, que la baña por el medio día. Está situada a los cuatro vientos con alguna declinación al oriente, para gozar en invierno, más temprano, de las influencias del sol. Por esta parte del mediodía se descubre un dilatado horizonte, que fenece en el mar océano sin que algunos cerros que tiene, a un lado y a otro, le estorbe su dilatada vista que, a distancia proporcionada, alcanza ver la ciudad de Cádiz, descubre su bahía y registra sus embarcaciones" ${ }^{\text {"13. }}$.

12 B. Gutiérrez (1757), Historia de Xerez de la Frontera, Vol. I, Jerez, 1989, 46-47.

13 E. Rallón, Historia de Xerez de la Frontera y de los Reyes que la dominaron desde su primera fundación, A. MARín y E. MARTíN (Ed.), 4 vols. Cádiz, 1997-2003, vol. IV, 174. 


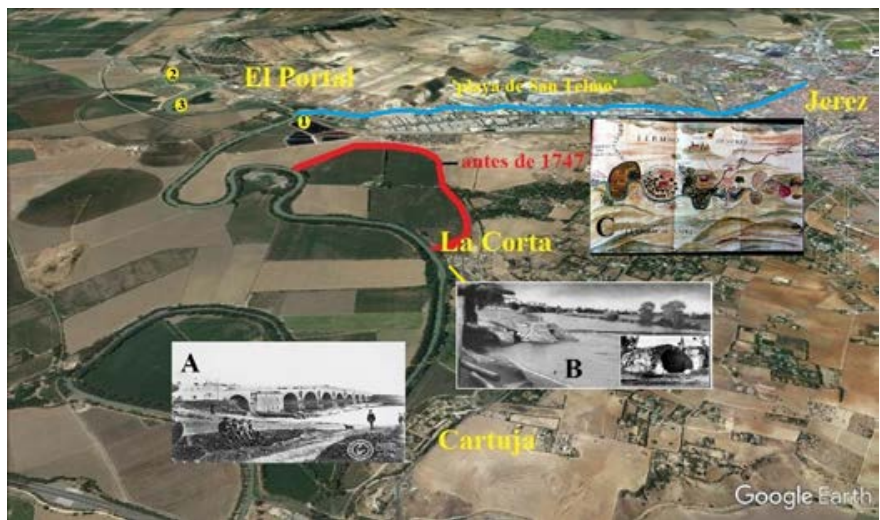

Fig. 3. El Guadalete y su entorno desde la Cartuja de Jerez: Google Earth ${ }^{14}$

Cerca se halla el lugar del Vado de los Hornos - que acaso aluda a los hornos que los cartujos construyeron en 1591 en las inmediaciones del monasterio, junto a la aceña del Rey -, donde hoy está la barriada rural de La Corta y estuvo, desde fecha imprecisa de la Edad Media, uno de los dos embarcaderos fluviales de Jerez (considerado por algunos autores el más antiguo). A mediados del s. XV ya era nombrado San Nicolás del Portal, por la inmediata ermita levantada bajo la advocación del santo de Bari, protector de los navegantes, que fue restaurada por el gremio de los barqueros en $1559^{15}$. Fue utilizado tanto por los barcos del comercio como por los pescadores de la ciudad, especialmente los dedicados a la 'almona', la pesca de los sábalos, que hasta el puente de Cartuja, donde alcanzaban las mareas, se introducían para desovar; pujante industria pesquera (practicada hasta mediados del s. XX) que fue motivo de continuos

\footnotetext{
14 A: Puente de Cartuja, colección de Fco. Lozano Romero. B: Embarcadero de La Corta e inmueble (¿batán?) de la Edad Moderna; Fondos Antiguos de la Universidad de Sevilla. C: Acuarela del curso bajo del Guadalete (1747) donde se marca la apertura del nuevo cauce junto a La Corta (Portal Viejo); Archivo Colombino de la Catedral de Sevilla (tomado de T. Falcón, 1993). 1-2-3: Ubicaciones de los embarcaderos de El Portal en la Edad Moderna.

15 H. SAnCho De Sopranis y J. DE LA LASTRA, Historia de Jerez de la Frontera desde su incorporación a los dominios cristianos, Jerez, 1965, Vol. II, 235.
}

«Las intervenciones antrópicas en el curso bajo del Guadalete... » 
conflictos entre los pescadores jerezanos y portuenses, al menos durante la segunda mitad del s. XVI ${ }^{16}$.

Lugar La Corta -el Portal Viejo que llaman los documentos del s. XVIII -donde hasta tiempos recientes se ha conservado una estructura escalonada, de hormigón y sillares, que se ha identificado con un embarcadero o presa de época romana ${ }^{17}$; seguramente la "fábrica antigua y de bastante consistencia", se decía en 1795, con que estaba "defendida la frente del río" 18 . Junto a estos vestigios aún quedan restos de un recinto abovedado que acaso por su fisonomía corresponda -y como es llamado por tradición oral- a un batán de la Edad Moderna (Fig. 3, B). En 1747, un largo tramo del río inmediato al Portal Viejo se encontraba tan colmatado e imposibilitada la navegación que le fue preciso al Cabildo jerezano cavar un nuevo cauce, que es el que ha llegado a nuestros días en el entorno de las tierras y cortijo de Río Viejo (Figs. 3 y 5).

Río abajo, el Guadalete se introducía (junto a la actual estación depuradora de aguas residuales) por el arroyo subsidiario de antiguo nombrado Guadajabaque ('río de la Red') hasta el pie del cerro donde se levanta Jerez, ocupando terrenos excavados durante la formación del estuario: los terrenos de La Hoyanca o la 'playa de San Telmo' de la historiografía y la tradición oral jerezanas (Figs. 3-4), espacio donde en el Medievo se asentó el barrio del gremio de los barqueros y pescadores jerezanos, levantándose arriba del cerro, en el s. XV, la ermita de su patrón San Telmo. Se conoce que en 1424 se construyó en su curso una azuda o presa, seguramente levantada para impedir o limitar que las crecidas del Guadalete, como de hecho ocurría, inundara hasta

\footnotetext{
16 J. Ferrer Andrade, "La pesca del sábalo en el río Guadalete", Revista de Historia de El Puerto, 14, (1995), 28.

17 R. GonzÁlez Rodríguez et al, Carta Arqueológica Municipal de Jerez. 1: El núcleo urbano, Jerez de la Frontera, S. A., 91 y 96.

18 Archivo Histórico Municipal de Jerez (AHMJ), legajo 153, exp. 4656.
} 
hacerlos intransitables los terrenos inmediatos a los accesos de la ciudad $^{19}$. Del mismo modo, por entonces se construyó otra azuda aguas arriba del Vado de Cartuja, al paso del río por la ermita de La Ina (s. XIV), donde los pescadores fluviales de Jerez también tenían sus pesquerías ${ }^{20}$.

Varios fueron los proyectos que se barajaron durante los siglos XVI y XVII para convertir a la propia ciudad de Jerez en un puerto fluvial, acercando el Guadalete a través de canales artificiales hasta el pie de la población, junto a la ermita de Guía o la Puerta Nueva del Arroyo, donde se previeron construir muelles o dársenas para la carga y descarga de las mercancías, nunca culminados por problemas de financiación: el más antiguo, de 1564, del ingeniero Guillermo Banesque; el más completo y ambicioso, preparado para acoger la Flota de Indias, el de fray Ambrosio Mariano Azaro, de 1581, que al año siguiente presentó en la Corte de Felipe II (Fig. 4) ${ }^{21}$. (Aún en el s. XX, en 1946, se retomó la antigua iniciativa, proyectándose un canal de derivación del Guadalete entre El Portal y San Telmo) ${ }^{22}$.

19 E. Martín Gutiérrez, La organización del paisaje rural durante la Baja Edad Media. El ejemplo de Jerez de la Frontera, Sevilla, 2004, 191.

20 IDEM., "La época cristiana (1264-1492)", D. CARo CANCELA (Coord.), Historia de Jerez. de la Frontera, 3 vols., Cádiz, 1999: vol. I, 327.

${ }^{21}$ N. García TAPIA, Ingeniería y Arquitectura en el Renacimiento español, Valladolid, 1990, 472-475. A. M. Cuadrado Román, "Los canales de Jerez", Revista de Historia de Jerez 14-15, (2008-2009), 67-90. IDEM, "El canal de Guadajabaque (I). Historia de un proyecto", Diario de Jerez, 20-XI-2012. IDEM, "El puerto de Jerez. El proyecto secreto de Felipe II", Diario de Jerez, 2-VI-2013.

22 J. Machimbarrena AguirrebengoA, "Las comunicaciones terrestres del Puerto de Cádiz”, Revista de Obras Públicas, 2807, (marzo 1949), 97-104.

«Las intervenciones antrópicas en el curso bajo del Guadalete... » 


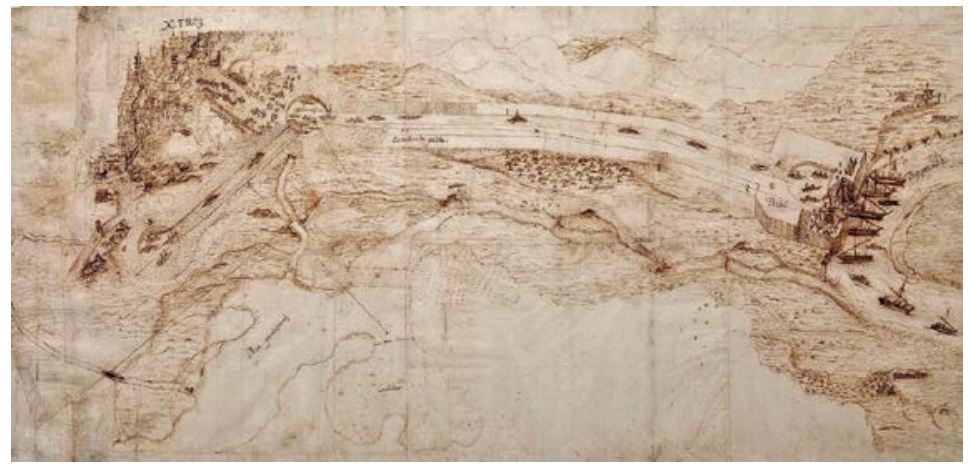

Fig. 4. Proyecto de A. Mariano Azaro

para convertir a Jerez en puerto fluvial (1581)23

Y otros planes, aún más ambiciosos, pretendieron el enlace del Guadalete con el Guadalquivir a través de Jerez: Guillermo Brane, 1525; Marcos Burriel, 1532; Leonardo Torriani, 1624; Cabildo de Jerez, 1632; Consejo de Castilla, 1715; Cabildo de Jerez, 1797; la jerezana Sociedad Económica de Amigos del País, $1834-1844 \ldots{ }^{24}$. Colosales proyectos que no se materializaron, no tanto por su elevado costo y las dificultades técnicas sobre el terreno sino por los contrarios e insalvables intereses económicos que Jerez mantenía con El Puerto, Sanlúcar y Sevilla.

Estos proyectos frustrados pretendieron dar respuesta a las deficientes y escasas infraestructuras que Jerez siempre tuvo en sus muelles fluviales de La Corta y, especialmente, de El Portal, que creemos que siempre fue, ya en tiempos de Alfonso

\footnotetext{
23 Real Biblioteca, Madrid. A la derecha, el muelle de El Portal a construir -con una esclusa para el paso de los barcos- y el canal navegable (12.900 pies de longitud por 30 de anchura) con dos dársenas circulares a los pies de la ciudad, en la Cuesta de San Telmo y La Alcubilla. El fin último del proyecto pretendía que en Jerez atracara la Flota de Indias, y no en Sevilla, evitando que los barcos del comercio con América remontaran el Guadalquivir y su peligrosa barra.

24 A. Hidalgo Ortega, Noticias sobre el proyecto de hacer puerto a Jerez, Jerez, 1881. A. M. CUADRADO ROMÁn, "El canal de Guadajabaque.
} 
$\mathrm{X}$, el principal lugar de embarque de los productos destacadamente el vino - del extenso alfoz jerezano. Al que se accedía desde los terrenos inundables de la marisma de la 'playa de San Telmo' por un pésimo camino que no se arrecifó hasta 1757; el cual, no obstante, continuó siendo intransitable para los carros en tiempos de lluvias. Por ello, el muelle del viejo Portal de San Nicolás, asentado su entorno en terrenos firmes, fue, pese a sus carencias, la alternativa de embarque de los navíos comerciales hasta fines del s. XVIII ${ }^{25}$.

Tres enclaves ocuparon los muelles de El Portal, a los que cabría llamar 'los Portales' (Figs. 3 y 5): el más antiguo y más próximo a la ciudad, junto a la boca del arroyo Guadajabaque; en El Portalillo, donde a comienzos del s. XIX se encontraba una barca de paso del río, junto a la muy antigua ermita de Nuestra Señora del Portal ${ }^{26}$, quizás donde ya en 1494 se encontraba la 'barca del Portal" ${ }^{27}$; y entre ambos, en el torno del Álamo, en terrenos de marisma distantes del suelo firme, junto al puente de la Herradura (que acogió el último muelle, el de los areneros, utilizado por éstos hasta la década de 1960).

Al menos desde comienzos del s. XVII la navegación por el entorno de 'los Portales' era realmente complicada a causa de los meandros, tornos y bajos que el río había formado, produciendo aterramientos que dificultaban el atraque en los modestos muelles y que repetidamente tuvieron que ser recompuestos y construidos de nuevo de cuando en cuando. Una intervención antrópica empeoró la situación a raíz de que el Cabildo, tras el saqueo de Cádiz por los ingleses en 1596 y con el

\footnotetext{
${ }^{25}$ En 1795 se trasladaron, quizás definitivamente, a El Portal. J. FERrER ANDrAdE, "La pesca del sábalo en el río Guadalete".

26 B. GutiÉrRez, Historia de Xerez de la Frontera, vol. II, 328.

27 Ibidem B., 298. J. Abellán PÉrez, "Las barcas del Guadalete: Las relaciones entre la villa de El Puerto de Santa María y la ciudad de Jerez de la Frontera en época de los Reyes Católicos", Revista de Historia de El Puerto, 47, (2011), 9-23.
}

«Las intervenciones antrópicas en el curso bajo del Guadalete... » 
fin de cerrar el paso a una eventual llegada del enemigo por el río, mandó hundir junto al Guadajabaque una galera, acción que no hizo más que crear el 'bajo de la Galera'28.

Para remediar estos males, a solicitud del Cabildo al rey vino a Jerez en 1612 el ingeniero militar Cristóbal de Rojas, que presentó entonces un proyecto para eliminar los meandros entre el bajo de la Galera y la 'barca de Puerto Franco' (Fig. 5), evitando el largo recorrido del río por el torno del Álamo (5500 varas $=1750 \mathrm{~m})$ y abriendo entre ambos puntos un canal para que "pase el río a vía recta por frente de ello"; pero la obra no se realizó. El nuevo muelle, de cantería, que previó construir sí se levantó al paso de unos años, en 1618, aunque perduró poco tiempo. Un plan similar al de Rojas lo presentaría en 1621 Julio César Fontana, que incluyó la construcción de un puente de dos arcos que salvara el río, pero tampoco se materializó ${ }^{29}$.

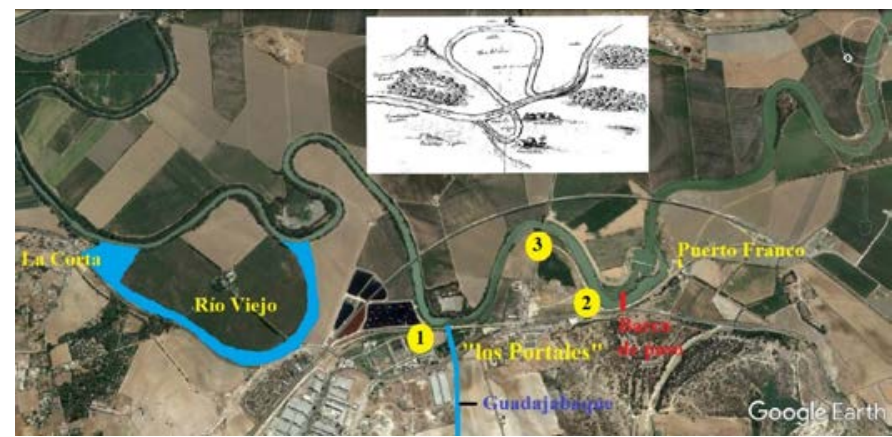

Fig. 5. Ubicación de los embarcaderos jerezanos ${ }^{30}$

\footnotetext{
28 B. Gutiérrez, Historia de Xerez de la Frontera, vol. II, 15.

29 E. De los Ríos Martínez, "Los informes de Cristóbal de Rojas y Julio César Fontana para hacer un muelle y un puente sobre el río Guadalete en Jerez de la Frontera", Laboratorio de Arte, 14, (2001), 13-25.

${ }^{30}$ La Corta (Portal Viejo). El Portal: 1-estación depuradora, junto al Guadajabaque, lugar del bajo de la Galera; 2-El Portalillo; 3-La Herradura. Y Puerto Franco. Google Earth. / Boceto (1747) del proyecto para atajar los meandros en El Portal entre el bajo de la Galera y Puerto Franco. Junto al Guadajabaque, el 'torno chico' que entonces se cegó antrópicamente. Archivo Municipal de Jerez.
} 
Tuvo que pasar más de un siglo para que se retomaran los viejos proyectos de Rojas y Fontana de abrir el mismo cauce recto. Fue en 1747 -el año que se excavó el nuevo curso del Guadalete junto a La Corta -cuando se volvió a intentar, pero nuevamente infructuosamente salvo que sí se eliminó el torno chico que existía en el curso del Guadajabaque (en Fig. 5).

El muelle de El Portal, con las dificultades que le fueron inherentes durante siglos, dejó de ser el puerto fluvial de Jerez a partir de 1856, cuando se inauguró, pasando por El Portal, la línea férrea entre Jerez y El Trocadero, que hasta 1922 fue la vía de salida al mar del vino jerezano de cara a su exportación.

Próximo a El Portal, junto al arroyo del Carrillo o Matarrocines que pasa a los pies de los cerros de La Bola y de San Cristóbal (Fig. 2) y en linde a los términos jerezano y portuense, se proyectó habilitar en 1500 otro puerto fluvial, de nombre Puerto Franco y efímera vida (Figs. 5-6). Aquel año se firmó un convenio entre Jerez y San Vicente de la Barquera por el que los pescadores de la villa cántabra que pescaran con sus pinazas en las costas del atlántico andaluz obligadamente tenían que traer el pescado y venderlo en el Puerto Franco, bajo pena, de no cumplirse lo acordado, de 10.000 maravedís. A cambio, cada pescador, entre otras franquicias y prerrogativas menores, podría sacar cada año un cahíz de trigo para su manutención, libre de aranceles. El convenio fue sancionado por Real Provisión de los Reyes Católicos en 23 de octubre de 1501, fijándose que los cántabros debían pagar $4 \mathrm{mrs}$. por docena de pescados descargados, dos para las rentas reales y dos para las casas que se construyeran en el lugar, cuya población se pretendía potenciar ${ }^{31}$. Las escasas fuentes documentales que de aquel tiempo nos han llegado no se hacen eco -al menos no nos consta -de qué pasó

31 A. Muñoz GómeZ, Dos documentos curiosos de los siglos XV y XVT. Convenio entre Jerezy los pescadores de San Vicente de la Barquera, Jerez, 1892. IDEM, Más documentos inéditos de los siglos XV y XVT. La pesquería de Puerto Franco, Jerez, 1892.

«Las intervenciones antrópicas en el curso bajo del Guadalete...» 
con el proyecto. Sí es conocido que en 1524 se establecieron nuevos acuerdos entre los pescadores de San Vicente y, ahora, El Puerto de Santa María, bajo condiciones más ventajosas para los cántabros -principalmente en el abasto de la imprescindible sal de sus salinas-, por lo que los pescadores, abandonando sus pesquerías con los jerezanos en fecha incierta, se asentaron en la villa señorial, desde 1370 propia de los duques de Medinaceli; que fue uno más de los desencuentros que de antiguo sucedían a causa de los intereses enfrentados y la rivalidad entre la villa ducal y la ciudad real, principalmente en lo concerniente al tráfico por el curso del Guadalete.

Cuando se firmó el convenio con Jerez en 1500, la ciudad ya tenía establecida en el lugar -a la vez que la existente en El Portalillo para navegar por el río -una barca de paso para alcanzar al otro lado de las marismas el camino Real de Cádiz que de muy antiguo la bordea. Que podría vincularse con los restos de un embarcadero y una embarcación hallados en 1980 en el inmediato azud de El Portal, que fueron fechados -por las cerámicas exhumadas a ellos asociados -a fines del s. XIII o comienzos del $\mathrm{XIV}^{32}$, si bien una revisión del material cerámico debería retrasar su datación al menos a los inicios de la Edad Moderna ${ }^{33}$. Fue la barca de Puerto Franco el precedente de la que con el mismo fin estableció Jerez en 1767, enfrente, en el antiguo curso del San Pedro (el actual Guadalete, vide infra), que sería conocida por el apellido de la familia que por arrendamiento la explotó: la barca de Florindas (en Fig. 8).

En Puerto Franco, en el linde de ambos términos se conoce que en 1525 -se menciona en una visita de términos que

\footnotetext{
32 F. J. Blanco JimÉnEZ, "Restos de una embarcación medieval en 'El Portal', Boletín del Museo de Cádiz, II, (1979-1980), 77-86.

33 Información oral de José Antonio Ruiz Gil.
} 
realizó entonces el cabildo de El Puerto - existía una venta propia de Pedro Franco aneja a una torre, de origen desconocido ${ }^{34}$.

En tierras limítrofes a Puerto Franco se encuentra al pie de la Sierra de San Cristóbal el pago de Sidueña, donde durante toda la Edad Moderna -y antes y después -estuvo activo un embarcadero de relevante importancia, al pie de la torre de Doña Blanca y junto a las célebres huertas de Sidueña (las que por su frondosidad y belleza diversos historiadores del s. XVII y XVIII vincularon con los míticos Campos Elíseos). Fue el lugar de embarque de los dos principales recursos naturales de la Sierra de San Cristóbal: el agua de los manantiales de La Piedad, sitos junto al muelle, donde arribaban, procedentes de El Puerto, los barcos comerciales y las galeras Reales para surtirse del líquido elemento durante el tiempo que invernaron en la ciudad (de forma permanente entre 1540 y 1668); y la piedra arenisca de sus canteras, con las que en buena parte se levantaron las ciudades de El Puerto y Jerez; de donde salió, vía fluvial, la mayor parte de la piedra empleada en la construcción de la catedral de Sevilla, por citar un ejemplo de tan importante industria extractiva.

\footnotetext{
${ }^{34}$ E. Pérez Fernández, J. J. López Amador, J. A. Ruiz Gil, “Arqueología histórica de los siglos XV-XVI en El Puerto de Santa María", Actas del Congreso El Puerto, su entorno y América', 14-16 octubre 1992, El Puerto, 1994, 53 y 57-58. En 1567 Wyngaerde dibujó la torre en lontananza en una de las vistas que tomó desde El Puerto. R. KAGAN, Ciudades del Siglo de Oro. Las vistas españolas de Anton van den Wyngaerde, Madrid, 2008, 309. La torre podría corresponder a la alquería andalusí de Bonaina que existió en el entorno de Puerto Franco.
}

«Las intervenciones antrópicas en el curso bajo del Guadalete... » 


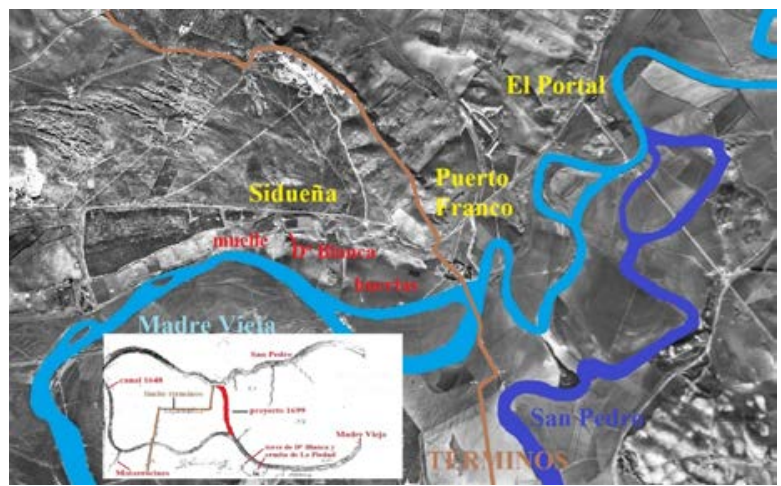

Fig. 6. Embarcaderos de Puerto Franco y Sidueña ${ }^{35}$

El curso del Guadalete que remontaban los barcos hasta el puerto de Sidueña -la 'madre vieja' o 'caño de La Piedad' que llamaban los portuenses -a mediados del s. XVII estaba colmado de bajos y meandros que dificultaban mucho la navegación, hasta casi hacerla inviable. Circunstancia que dio lugar a que Jerez, para remediarlo y en defensa de sus intereses, ejecutara una obra que de raíz cambió el paisaje fluvial y la propia historia del curso bajo del Guadalete hasta nuestros días. De esta obra antrópica y de los largos litigios que generó tratamos a continuación.

\section{La comunicación del Guadalete al San Pedro por el olivar de Cartagena (1648).}

El 24 de mayo de 1648 las autoridades jerezanas acordaron cerrar el comercio y suministro de víveres con $\mathrm{El}$ Puerto de Santa María. El motivo aducido, evitar el contagio de la peste bubónica que por entonces se había asentado en la vecina

\footnotetext{
35 En el límite de los términos municipales de Jerez y El Puerto, con el trazado de la desaparecida 'madre vieja' del Guadalete (celeste) y el río San Pedro (azul); detalle de fotograma del vuelo americano de 1956. Croquis de la cortadura que se pretende hacer en el río San Pedro por el sitio de la Vega jurisdicción del Puerto para su comunicación con el río Guadalete; leyenda del boceto de Antonio Osorio, 1699, Archivo Municipal de Jerez. En el lugar que ocupa la torre de $\mathrm{D}^{\mathrm{a}}$ Blanca existió la ermita de Nuestra Señora de Sidueña (h. 1285-h. 1563). Junto a los manantiales de La Piedad, la ermita de su nombre, levantada a comienzos del siglo XVIII.
} 
ciudad $^{36}$. A comienzos de julio ${ }^{37}$, bajo el auspicio de la cofradía de San Pedro, el Cabildo jerezano adoptó, supuestamente con el mismo fin, otra medida: unir el curso del Guadalete al del Salado de Puerto Real a la altura del olivar de Cartagena, en el paraje de El Granadillo, desde donde se excavó una zanja algo menor a 400 pasos geométricos (560 metros), resultando que

“...habiendo roto más de mil varas de tierras y dejando el río Guadalete con dos bocas al mar, recibiendo por esta nueva tanta agua salada que lo hizo más caudaloso y subió más de una legua arriba" 38 .

Era en linde al olivar -propio de Luis de Cartagena donde el Guadalete se aproximaba más (apenas 500 metros) al Salado, los olivos flanqueados por ambos cursos a modo de un islote, por lo que fue, junto a su proximidad al embarcadero de El Portal -el emplazado entonces en El Portalillo -el lugar elegido por las autoridades jerezanas para que los barcos pasaran del Guadalete al Salado (Figs. 6-7). Este era el principal emisario del Guadalete, de antiguo nombrado Salado o Saladillo de Puerto Real, hasta que en 1648, con la intervención de la cofradía de San Pedro como patrono en la apertura, mudó su nombre por el de San Pedro, aunque desde El Puerto lo continuaron llamando por su viejo nombre. Como abajo indicaremos (epígrafe 4), a comienzos del siglo XVIII se cerró su cauce para unirlo a la 'madre vieja' y desde entonces es un brazo de mar cegado, alimentado por las mareas. Habría que entender el patrocinio de la obra por la cofradía de San Pedro como un acto por el que el

\footnotetext{
${ }^{36} \mathrm{La}$ incidencia de la peste en El Puerto y las medidas de protección que se adoptaron, en E. Pérez Fernández, "Por orden del Duque mi señor...", Pliegos de la Academia, 5, (1992), 20-22. El cierre del comercio lo secundaron al paso de unos días las poblaciones vecinas: Cádiz, Puerto Real, Rota y Chiclana. La epidemia terminó extendiéndose por gran parte de Andalucía.

${ }^{37}$ AHMJ, Actas Capitulares de 1648, cabildo de 15-VII, f. 182.

${ }^{38}$ E. RALlón, Historia de la ciudad de Xerez de la Frontera, 99.
}

«Las intervenciones antrópicas en el curso bajo del Guadalete... » 
Cabildo jerezano, consciente de que la obra ejecutada era ilegal, se amparaba en la Iglesia como quien se acoge a sagrado.

Se materializó en 1648 lo que un cuarto de siglo antes, en 1624, el ingeniero de Felipe II Leonardo Torriani (citado arriba) planteó como alternativa, en caso de no realizarse su plan de unir el Guadalete al Guadalquivir, para dar salida a la bahía de Cádiz a los productos jerezanos desde El Portal. Canal que recomendaba abrir en la barca de Puerto Franco, debiéndose excavar 4000 pies de tierra $(1100 \mathrm{~m})$ hasta unirlo al Salado; el doble del terreno que finalmente se abrió ${ }^{39}$.

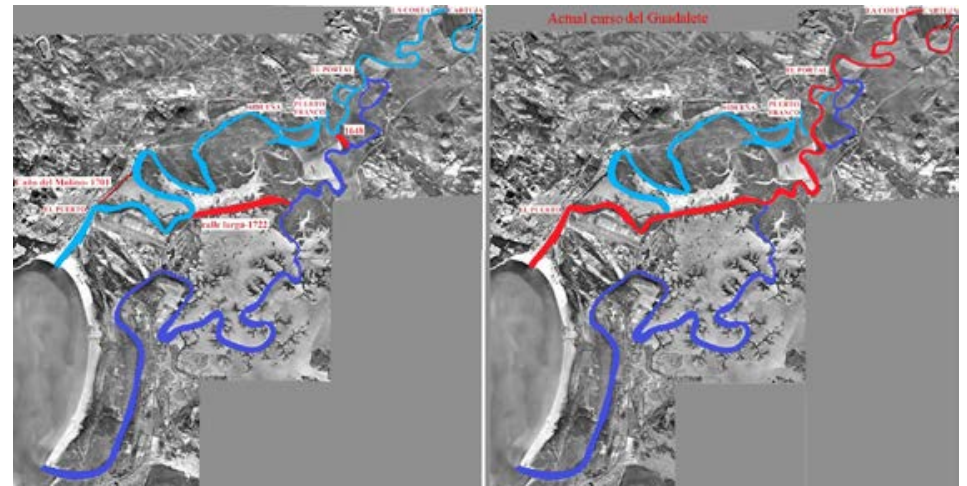

Fig. 7. Las tres principales obras antrópicas (en rojo) realizadas en el curso bajo del Guadalete y San Pedro en la Edad Moderna. Vuelo americano de 1956. I A la derecha, el curso por el que boy corre el Guadalete (en rojo) y al sur el hoy brazo de mar del San Pedro.

En las Figs. 6-7 se observa el trazado que tuvo el Salado hasta fecha imprecisa -en el entorno de su confluencia con el Guadalete a la altura de El Portal (según Mapa Geológico de España, Hoja 1062-Paterna de Rivera). Desde aquí y en un largo

39 D. SuÁrez Quevedo, "Navegación fluvial e ingeniería militar en España, siglos XVI-XVII. De Pérez de Oliva y Antonelli, a Leonardo Torriani y Luis Carducha", Anales de Historia del Arte, 17, (2007), 148-150. El informe del ingeniero italiano está fechado en Madrid en 17 de julio de 1624. 
tramo, el Salado a comienzos del s. XVII -y probablemente desde unos siglos antes -debía encontrarse plenamente colmatado e imposibilitada la navegación, porque si no, no hubiese sido preciso abrir aguas abajo el canal que finalmente Jerez excavó en 1648 para unir ambos cursos y así evitar el paso por la colmatada 'madre vieja' del Guadalete.

La peste fue la justificación que Jerez adujo para abrir la comunicación pero, en verdad, también terciaron motivos económicos de gran calado e intereses encontrados entre una ciudad realenga -Jerez- y otra -El Puerto- de régimen señorial, propia del ducado de Medinaceli. Comenzó en el verano de 1648 un período, prolongado hasta 1722, de continuos enfrentamientos y pleitos entre ambas ciudades; en certeras palabras de Hipólito Sancho, un "pleito enojosísimo, violento, enmarañado, lleno de pasión" $"$.

A petición del Gobernador de Jerez, don Francisco Dávila, en el mismo año de 1648 se publicó un folleto "para que Su Magestad y su Consejo supremo de Castilla sean informados en este caso con certeza", dándose cuenta de las razones, más allá de la protección ante la peste, que motivaron la actuación jerezana ${ }^{41}$. La raíz del asunto venía de los inconvenientes que presentaba la navegación por el Guadalete:
"consta este río desde el Portal a su boca de muchos bajos, que obligan en cada uno a alijar [desembarcar] las pipas de vino, que es el principal fruto que se carga [...] esperando tantas mareas de pleamar para embarcarlas, y pasar de bajo en bajo."

\footnotetext{
${ }^{40}$ H. SAnCho De Sopranis, Historia del Puerto de Santa Maria desde su incorporación a los dominios cristianos en 1259 hasta el año mil ochocientos, Cádiz, 1943, 333.

${ }^{41}$ Discurso demostrable en desengaño de las causas que dieron motivo a abrir la comunicación de el Salado al rio Guadalete (folleto folio menor, 7 hojas), Jerez, 1648.
}

«Las intervenciones antrópicas en el curso bajo del Guadalete... » 
Nueve eran los bajos que tenía el Guadalete desde El Portal (en El Portalillo) hasta la desembocadura en El Puerto de Santa María (Fig. 8): El Granadillo (salvado tras la apertura), Puerto Franco, La Isleta, Sidueña o La Cantera Vieja (frente a la torre de Doña Blanca, en alusión a las ruinas de la ciudad fenopúnica), El Carrizal, La Esparraguera, La Cantera del Palmar ${ }^{42}$, Las Salinas y el del Puerto. Y con los bajos, otros tantos tornos que dificultaban aún más la navegación, por lo que la travesía entre El Portal y El Puerto se prolongaba durante, al menos, cinco días (sic).

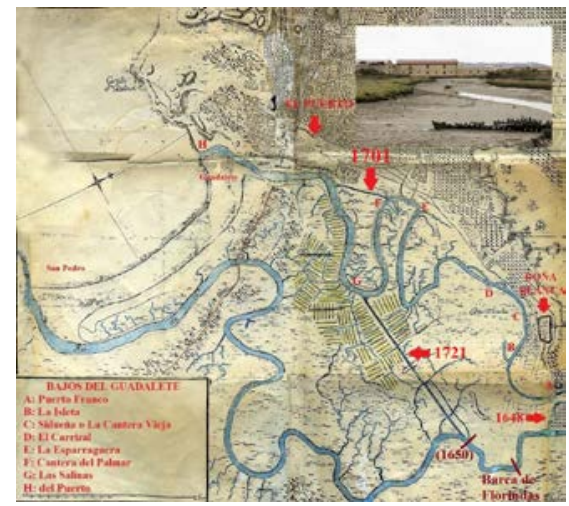

Fig. 8. Situación de los bajos del Guadalete en plano de $1750^{43}$.

Respecto a la preciada mercancía embarcada se indicaba en el folleto que "como se conducen las pipas o botas por el agua, muchas veces se hinchan de ella y se estragan [se vician] y hacen caliche los vinos, conque han bajado y bajan de precio los

\footnotetext{
${ }^{42}$ De este lugar dice el folleto: "El séptimo bajo es la cantera del palmar, es bajo de piedra viva en partes, y en partes de montones de piedras, y dura por tradición la memoria que estas piedras las juntaron los antiguos Romanos y Turdetanos, para hacer arrecife aquel paraje". De estos vestigios antrópicos, ya desaparecidos, venía el viejo dicho portuense "Tiene más años que el Palmar". Lo mencionaba Antonio Alcalá Galiano en sus Recuerdos de un anciano (1864, cap. IX): "Cuando en los pueblos de la Andalucía baja, vecinos a la costa, se habla de una persona de mucha edad, y quiere ponderarse su vejez, es común decir de ella que tiene más años que el Palmar del Puerto."

43 Antonio Rodolpho. Servicio Geográfico del Ejército. / Actual embocadura del caño del Molino. Foto, Agustín García Lázaro.
} 
de Xerez respecto a los de Sanlúcar y el Puerto"; estimándose que las alcabalas del vino jerezano habían bajado en torno al 25\% ${ }^{44}$. Esta era la principal razón defendida por Jerez para unir el Guadalete al San Pedro. El curso de éste, por contra, no tenía ningún bajo y sólo tres tornos, por lo que se podía llegar a su desembocadura al mar en La Cabezuela en medio día, seis horas de navegación.

Y una segunda razón, no enunciada por Jerez pero también principal, era que con la salida al mar por el término de Puerto Real los barcos del comercio jerezano evitaban pagar los tributos fijados por el señorío portuense, motivo in illo tempore de repetidas disputas y desencuentros entre ambas localidades por el derecho o no que tenía la villa señorial de cobrar a las naves jerezanas los derechos de anclaje y de a monte; desencuentros que fueron especialmente virulentos a partir de la segunda mitad del siglo XV. Puerto Real, en cambio, era villa realenga desde su fundación por los Reyes Católicos en 1483, y dependiente del Concejo de Jerez desde 1488 y hasta 1543, por lo que los jerezanos tuvieron con el Puerto Real una estrecha vinculación. Desde El Puerto la apertura por el olivar de Cartagena se contempló con otros ojos: la pérdida de los tributos que pagaban los barcos jerezanos y la pérdida de caudal que la obra supondría a la 'madre vieja', ya por entonces, como vemos, muy menguada.

El caso es que tras la apertura del canal, El Puerto interpuso una querella a Jerez ante el Consejo de Castilla, que terminaría resolviendo a su favor tras un pleito que se fue dilatando en el tiempo. No obstante, en la resolución favorable a los intereses portuenses no poco debió influir la presencia en El Puerto del duque de Medinaceli, don Antonio Juan Luis de la

\footnotetext{
${ }^{44}$ Como botón de muestra, apuntamos que en 1643 se embarcaron en El Portal 9.425 botas de vino y vinagre (de 30 arrobas $=500$ litros) y 2.320 quintales de pasas. M. Ma GonzÁlez Gordon, Jerez-Xerez-Scheris, Jerez, 1935, 77. AHMJ, Act. Cap. 1643, cab. 31-VIII, f. 210.
}

«Las intervenciones antrópicas en el curso bajo del Guadalete... » 
Cerda, a la sazón Capitán General del Mar Océano y Costas de Andalucía, y su vínculo fraternal -por él corría sangre real -con las más altas instancias del Estado. Mientras el veredicto llegaba, las partes no permanecieron quietas. En 1650 los portuenses echaron a pique en la boca del canal una galera; "pero no surtió el efecto que se deseaba por entonces aunque contuvo algo" "45. Se planteó entonces un sagaz proyecto ordenado por el duque de Medinaceli: levantar un puente en el Salado, unos cientos de metros río abajo del canal, para que los ganados pudieran pasar al pasto común que El Puerto mantenía con Jerez y Puerto Real (en Fig. 8) ${ }^{46}$. Pero el proyecto escondía otra intención: el puente cerraría el paso de los barcos por el Salado; pero no sólo a los jerezanos, sino a todos los barcos comerciales, nacionales y extranjeros, que remontasen el río hasta el embarcadero de El Portal, por lo que el osado proyecto, que de haberse materializado habría causado un colapso económico, no se ejecutó.

Por fin, el 4 de abril de 1651 el Supremo Consejo dictó un auto ordenando a Jerez el cierre del canal ${ }^{47}$. Y Jerez lo cerró, pero de malas maneras, porque "añadiendo delito a delito y desacato a desacato, a pocos días con el primer creciente de aguas uno y otro cerramiento se abrieron y se puso la zanja corriente como los delincuentes lo quisieron poner y mucho más ancha y fondable y de manera que ya se navega por ella desde Cádiz a Jerez", maldecían desde El Puerto ${ }^{48}$. La respuesta a la afrenta la respondió el duque de Medinaceli mandando echar a la zanja piedras ostioneras que sacaron de la portuense playa de Santa Catalina, pero fue otro intento infructuoso ${ }^{49}$. Hubo otros autos del Consejo conminando a Jerez a cumplir lo mandado, siempre

\footnotetext{
45 B. Gutiérrez, Historia de Xerez de la Frontera, vol. II, 216.

46 AHMPSM, Act. Cap. 1650, cab. 9-V, f. 336v.

47 AHMPSM, Papeles Antiguos, leg. 75, $\mathrm{n}^{\circ} 4$.

48 AHMPSM, Papeles Antiguos, leg. 75, no 3.

49 AHMPSM, Act. Cap. 1652, cab. 19-II, f. 29.
} 
incumplidos ${ }^{50}$, hasta que una sentencia de comienzos de marzo de 1654 sí terminaría por cumplirse. Por ella se mandaba al Concejo de Jerez que procediera a perpetuidad al cierre de las dos bocas del canal, y en el caso de que no lo hiciera en el plazo de veinte días, lo ejecutara el de El Puerto con cargo a Jerez. Como era previsible, el plazo se agotó y el de Medinaceli mandó sacar 64.0000 reales del Pósito para iniciar las obras ${ }^{51}$. Finalmente, en ellas se emplearían 93.669 reales $^{52}$.

A la vista de la amplia y detallada documentación conservada en el Archivo Municipal portuense, el cierre de las bocas en el olivar de Cartagena fue una obra de envergadura, en la que se emplearon abundantes recursos económicos, materiales y humanos. La obra se prolongó del 23 de marzo al 8 de junio de $1654^{53}$. Fue dirigida por el Ingeniero mayor y capitán Gerardo Coen, asistido, entre otros, por el maestro de campo Francisco Vaños, el maestro mayor de obras Francisco Jiménez de Mendoza, el sargento mayor del Presidio de Cádiz Mateo Grajal y el síndico procurador mayor de El Puerto Mateo Dávila. El cierre de las bocas se realizó a base de formar estacadas (clavadas desde gabarras y reforzadas con riostras y tirantes), echando 1.625 carretadas de piedra (la mayoría, roca ostionera de Santa Catalina) y formándose un azud con cuatro taludes y terraplenes sellados con cajones macizos de madera. Para las estacadas se emplearon 1.029 pinos (cortados en longitud de 5 varas y media $=4,5 \mathrm{~m}$ ) y 1.760 tablas, todos comprados en Puerto Real, cargados en gabarras y traídos, como el resto del material pesado, por el San Pedro, porque por la 'madre vieja' del Guadalete, como bien sabían, hubiese sido una tarea ímproba. Entre otras herramientas,

\footnotetext{
50 AHMPSM, Papeles Antiguos, leg. 75, nº 4.

51 AHMPSM, Act. Cap. 1654, cab. 7-III, ff. 119v-120. J. GonZÁlez Moreno, El condado del Puerto de Santa María, Cádiz, 1989, 35.

52 AHMPSM, Act. Cap. 1655, cab. 24-VII, f. 163v.

${ }^{53}$ La mayor parte de la documentación de la obra se encuentra en los legajos 47 y 75 de la Sección Papeles Antiguos del AHMPSM y en numerosas Actas Capitulares.
}

«Las intervenciones antrópicas en el curso bajo del Guadalete... » 
se utilizaron 200 palas, 100 azadas, 100 espiochas, 100 pisones (para apisonar la tierra), 30 mazos roderos y 2 martinetes (para clavar las estacas). La mano de obra la componían esclavos moros que en las galeras Reales surtas en el Guadalete cumplían sus penas como galeotes -hasta 100 trabajaron durante el primer mes- y otros esclavos -hasta 83- propios de las familias pudientes de El Puerto, que fueron alimentados a base de pan y queso, salvo en alguna ocasión en que les dieron un quintal de bizcocho y medio millar de sardinas. Para el resguardo y custodia de los esclavos y materiales se construyeron junto a las bocas de los ríos seis barracas de madera, iluminadas con lampiones (faroles) de aceite, además de una tienda de las galeras. A la vigilancia de los esclavos se dedicaron dos comitres, un sotaalguacil y veinte marineros, todos personal de las galeras. Para inspeccionar las obras, en alguna ocasión visitó el lugar el todopoderoso duque de Medinaceli, en su coche, tras arreglarse para ello el camino de acceso a la obra. Y por no faltar, no faltó la presencia de un capellán que en días señalados ofició dieciséis misas, viniendo de El Puerto por el camino de Sidueña a lomos de una mula.

Para Jerez, el cierre del canal del olivar de Cartagena supuso que el tráfico de los barcos fletados en El Portal volviera a su situación anterior: bajando como podían por la 'madre vieja' del Guadalete. Y tras la obra, los problemas entre Jerez y El Puerto se redoblaron. Así apuntó el estado de la cuestión Juan José Iglesias:

"En 1654, el síndico procurador de aquella ciudad [Jerez] protestó por el embargo de que eran objeto los frutos que se enviaban a Cádiz a través de El Puerto y por otras molestias y retenciones que causaban las autoridades portuenses, con diversos pretextos, en el traslado de dichas mercancías. Cobraba el duque de Medinaceli en esta última ciudad un derecho de portazgo de siete reales por cada barco de trigo, más un canon de medio o un real por cada fanega de este 
producto. Esta exacción se realizaba sin facultad real y a pesar de que los vecinos de Jerez pagaban puntualmente los derechos de cientos y alcabala. [...] Puede que este tipo de obstáculos al normal desarrollo del comercio jerezano viniera determinado por el deseo de los vecinos de El Puerto de monopolizar a su favor el abastecimiento de Cádiz, que constituía una fuente de saneados ingresos. Puede, sin embargo, que se tratara, tan sólo, de la voluntad del duque de Medinaceli de conseguir pingües beneficios por el tránsito de mercancías a través de la zona de su jurisdicción. Lo cierto es que esta actitud motivó una contundente reacción por parte de los jerezanos, que intentaron desviar el cauce del río Guadalete por el Salado de San Pedro, obteniendo así una salida fluvial al mar por territorio de realengo. A esta medida se opusieron los portuenses, que veían seriamente amenazados de esta manera sus intereses mercantiles" 54 .

Pese a la solidez del azud levantado, a comienzos de enero de 1655 grandes avenidas derribaron parcialmente las estacadas, por lo que fue preciso su reparación, que se verificó entre el 14 de enero y el 25 de febrero ${ }^{55}$. Al paso de unos años, en el invierno de 1667 , nuevas crecidas volverían a dañar la obra ${ }^{56}$.

A pesar de los sucesivos intentos por parte de El Puerto para cerrar el canal y que las aguas del Guadalete volvieran a correr por la 'madre vieja', el curso que abrió Jerez por el olivar de Cartagena ha perdurado hasta nuestros días, por donde transcurre fundido al antiguo cauce del San Pedro. La opción portuense de mantener navegable la 'madre vieja', progresivamente más colmatada y con más bajos, era inviable. Hubo un último intento, en 1699, cuando el ingeniero Antonio Osorio presentó al Cabildo un proyecto para abrir, en término

\footnotetext{
54 J. J. Iglesias RodrígueZ, Una ciudad mercantil en el siglo XVIII: El Puerto de Santa María, Granada, 1991, 261-262.

55 AHMPSM, Act. Cap. 1655, cab. 16-I, f. 147 y cab. 22-II, f. 150v. Papeles Antiguos, leg. 47.

56 AHMPSM, Papeles Antiguos, leg. 75, nº 7.
}

«Las intervenciones antrópicas en el curso bajo del Guadalete... » 
portuense próximo al jerezano (tal como había hecho Jerez medio siglo antes), un canal por el que el San Pedro fluyera y alimentara a la 'madre vieja'; pero el proyecto, al no contar con la licencia del Estado para ejecutarlo, no se realizó (en Fig. 6).

El tramo del Guadalete entre el muelle de Sidueña y El Portalillo -el 'caño de la Piedra' que llamaban en Jerez definitivamente se dio por cegado el año 1800. Sí continuó siendo navegable, con dificultad, la 'madre vieja' o 'caño de La Piedad' desde El Puerto al muelle de Sidueña, hasta el último tercio del s. XIX, utilizado por barcazas que remontaban el río para cargar las aguadas de sus célebres manantiales ${ }^{57}$.

Cuando el ingeniero Osorio presentó al Cabildo el proyecto de apertura del canal, estaba trabajando también en un plan para la limpia de la barra del Guadalete, obstruida por bancos de arena que desde décadas atrás dificultaban muy seriamente, casi imposibilitaba, la navegación $\mathrm{y}$, por ende, el presente y el futuro de una ciudad en la que el comercio marítimo siempre había sido su principal fuente de recursos. A partir de entonces, aunque desde El Puerto continuó pidiéndose el cierre del curso del San Pedro para que sus aguas desaguaran por la 'madre vieja', la prioridad de la ciudad iba a ser el reparo de la boca del río.

\section{La limpieza de la barra del Guadalete y el atajo del caño del Molino (1699-1701).}

Tal vez no se halle en la historia de El Puerto de Santa María una actuación tan continuada como las obras de canalización y dragado del río Guadalete, presentes, sin solución de continuidad, desde los inicios de la Edad Moderna (1525)

57 Así, por ejemplo, en 1870 se creó en Cádiz una empresa -La Cruz, propia de José F. de Prado- dedicada a proveerse en el manantial de La Piedad, a donde diariamente llegaban barcos a cargar el agua para el consumo de los gaditanos, que la adquirían en los bajos de la muralla de la Puerta del Mar, a 17 reales la pipa. 
hasta nuestros días ${ }^{58}$, que determinaron, para bien o para mal, su desarrollo socioeconómico. Desde el traslado del invernadero de las galeras Reales al puerto de Cartagena en 1668, los intentos para limpiar la barra del Guadalete fueron constantes, pero la falta de fondos de los Propios de la ciudad aplazó tan principal obra año tras año, hasta que en 1698 el asunto tomó otro cariz. Entonces, el Consejo de Castilla concedió que se impusiera un arbitrio del $2 \%$ a todas las mercancías que entraran en la Aduana para aplicar el dinero al reparo de la barra ${ }^{59}$.

La traza de la obra fue encomendada al mencionado capitán Antonio Osorio, Ingeniero mayor de las Costas de Andalucía. Los trabajos se prolongaron del 12 de mayo al 22 de junio de 1699. Para romper la laja y extraer la arena y la zahorra de los dos bancos de arena de la barra se utilizaron un pontón con cuatro cucharas, una barcaza y cuatro lanchas (sacaban la piedra de la laja), trabajando en ellas 8 oficiales y 55 peones. El coste de las operaciones, 21.316 reales $^{60}$. Al paso de unos meses, en mayo de 1700, tras reconocer Osorio el estado de la barra, comunicó a la ciudad que

"aún persisten las dificultades y mal estado de la navegación por la falta de agua, suponiendo que esta proviene de la que le usurpa el caño del Salado, que con esta usurpación hoy se llama río de San Pedro, y que siendo éste el único motivo de tantos daños, es preciso y único remedio para que la barra vuelva a su antiguo estado, restituir al río sus aguas, y estando informado de los caballeros diputados de la obra que la restitución no puede ejecutarse pronto por ser preciso licencia del Consejo y

58 El 11-II-1525, el duque de Medinaceli, don Juan de la Cerda, ordenó al jurado Francisco Hernández Palomino y a Ruy López Calafat que procuraran la limpieza del río desde la embocadura hasta los pilares (del puente romano de la Vía Augusta) y desde aquí hasta que el río se adentraba en término de Jerez a Juan del Pozo. Archivo Ducal de Medinaceli (Sevilla): Caja 262, $\mathrm{n}^{\circ} 31$.

59 AHMPSM, Papeles Antiguos, leg. 75, n 11. Act. Cap. 1700, cab. 9-I, ff. 13-15.

60 AHMPSM, Papeles Antiguos, leg. 75, nº 12.

«Las intervenciones antrópicas en el curso bajo del Guadalete... » 
tener que pasar algún tiempo en conseguirla [cinco décadas llevaba El Puerto en ello], sin dilación se corten los dos tornos del río más próximos a la ciudad, llamados de la Victoria y de la Esparraguera, de modo que formen una línea recta"61.

Así pues, despuntando el siglo XVIII y transcurrido medio siglo de la apertura por Jerez del canal del olivar de Cartagena, se contempló, ahora por las autoridades portuenses, una segunda intervención para cambiar artificialmente el curso del río en los tornos y meandros de la 'madre vieja' más inmediatos a la ciudad. Y sin dilación, como pedía Osorio, las obras comenzaron el 5 de julio de $1700^{62}$. Con esta actuación, abriendo un caño en línea recta entre los tornos de la Victoria y la Esparraguera (o bajo y ensenada del Carrizal) -distantes 600 varas $=500$ metros - , se preveía que las aguas, fluyendo por la 'madre vieja' con más rapidez, iría quitando los bajos de la barra y detendría la acumulación de arenas aportadas por el viento de levante, amén de facilitar la navegación -en una sola marea, se necesitaban dos- a los barcos que remontaban el río para hacer las aguadas en Sidueña (Figs. 7-8). El atajo del caño acortaría la navegación en más de 3.000 varas, 2.500 metros. Para culminar la obra fue preciso construir una 'esclusa de limpia' en el torno de la Victoria:

"por donde el canal recoja agua todo el tiempo que monta la marea, quedará un almacén de más de doce mil varas [10 km], y plena la marea se cerrarán las puertas, que no se abrirán hasta el agua escorada. Esta agua detenida, con la violencia que saldrá, podrá arrancar en todas las mareas los bancos de arena de la barra." 
La esclusa o dique se construyó entre el 4 de enero y el 7 de febrero de 1701 (1.961 rs. $)^{63}$, mientras continuaban las tareas de apertura del canal, que se prolongaron hasta comienzos de septiembre $^{64}$.

El curso del 'caño de la madre vieja' -como era conocido antes de que en 1815 se levantara sobre su cauce el molino mareal harinero que hoy lo nombra ${ }^{65}$-ha llegado a nuestros días parcialmente $(350 \mathrm{~m})$, algo menos de la mitad de su longitud original. Su cauce está prácticamente cegado, cubriéndose solo de aguas superficiales en las mareas altas (en Fig. 8). La prolongación del antiguo curso aún se percibe entre las parcelas del polígono industrial San José, hasta la calle Ensenada. Antes de construirse esta zona industrial, hasta los años sesenta eran visibles los meandros "fosilizados" de la 'madre vieja', que dejó de llevar agua a comienzos del s. XX, asfixiada y cegada por los sedimentos que durante siglos colmataron su curso.

La obra de 1701 vino a ser una solución estéril, realizada un tanto a la desesperada y sin viso de que resultara efectiva, como bien sabía Osorio. El escaso caudal de la 'madre vieja', frenado por la acumulación de bajos y meandros en su curso, impedía que las aguas irrumpieran con fuerza en la desembocadura para limpiar la barra. Decía Osorio (supra) que era "preciso y único remedio para que la barra vuelva a su antiguo estado, restituir al río sus aguas", a lo que El Puerto nunca renunció, gestionando durante años a través de sus agentes en la Villa y Corte el viejo anhelo. Pero a pesar de duplicarse los esfuerzos tras la fallida apertura del caño del Molino, tuvieron que transcurrir dos décadas para que se materializara el cierre del curso del San Pedro. Fue la tercera intervención en la Edad Moderna por la que

\footnotetext{
63 AHMPSM, Act. Cap. 1702, cab. 1-I, f. 5v-6.

64 AHMPSM, Act. Cap. 1701, cab. 4-XI, f. 118v-123.

${ }^{65}$ L. Márquez Carmona, "El molino mareal del caño de El Puerto de Santa María", Revista de Historia de El Puerto, 40, (2008), 81-102.
}

«Las intervenciones antrópicas en el curso bajo del Guadalete... » 
por la mano del hombre se modeló los cursos del Guadalete y del San Pedro.

\section{El cierre del San Pedro y su enlace al Guadalete: la 'calle larga' (1721-1722).}

Al tiempo que se limpiaba la barra del Guadalete en 1698, el San Pedro ya no fluía con la fuerza y limpieza que medio siglo atrás. De ello se quejaba entonces El Puerto:

“...con las ramas y brozas que lleva de las avenidas ha creado un bajo que vulgarmente llaman la Cabezuela que llega hasta media bahía, sin poder salir ni entrar los navíos en Puntales sin riesgo, pues se cerrará totalmente el uso de Puntales. [...] En el Guadalete la salida es en mar ancha y sobre la costa de Santa Catalina y los Cañuelos, sin causar daño a la bahía. [...] solo transitan por el Salado cuatro gabarras de Jerez de particulares con sus botas de vinos de sus cosecheros y de retorno alguna duela o bacalao" 66 .

Para conocer el estado pasado, presente y futuro de ambos ríos a fines del s. XVII, valdrá reproducir un testimonio, de diciembre de 1698, de quien era el alcaide de la mar portuense, Juan de Soto, que en declaración jurada contó:

"que este testigo conoció y vio navegable este río [Guadalete] por arrimado a la casa del olivar de Cartagena, por donde iban y venían los barcos y gabarras hasta el Portal viejo cargados de frutos, y desde allí trajinaban por este río para los que iban a Cádiz y su bahía sin riesgo alguno, lo que ahora sucede y se pierden muchas embarcaciones cargadas de frutos por el otro río a la salida de él, por la violencia y rápido de las aguas, y restituyendo las aguas usurpadas al Guadalete y atajando el curso que hoy tiene el Salado por el olivar de Cartagena, no sólo no se sigue perjuicio alguno a Jerez para la navegación que quieran hacer y transporte de sus frutos a Cádiz y bahía, que es

${ }^{66}$ AHMPSM, Papeles Antiguos, leg. 75, $\mathrm{n}^{\circ} 9$. 
para lo que hoy se sirven del Salado, sino es que antes bien, recibirán en ello gran utilidad, así porque viniendo las aguas congregadas por su antiguo y natural curso que tenía el Guadalete, será la navegación más breve y segura porque cerrándose como se cierra el paso de Jerez a ésta por tierra con las lluvias del invierno, por ser de mala calidad el terreno barrizal, no se puede transitar por los atolladeros y malos pasos ${ }^{67}$, le tendrán franco y abierto por el río que este testigo conoció que desde el Portal de Jerez se venía la gente en barquillos a esta ciudad y a la de Cádiz para proveerse de sus bastimentos, y que sucederá lo mismo ahora cerrándose el Salado y solo pueden aspirar a la navegación por él los que intenten cometer fraudes en perjuicio de la Real Hacienda por lo dilatado que es y despoblado, sin el Regimiento de guardia y custodia que por la Real Aduana y demás rentas se pone en este río"68.

Importante cuestión ésta de los fraudes que se cometían con la Hacienda para que finalmente se resolviera el largo litigio en 1721, cuando se cortó el cauce del San Pedro. Pero el cierre no se efectuó, como se pretendió durante décadas, por el olivar de Cartagena - el curso de la 'madre vieja' con sus bajos, meandros y tornos no daba mucho más de sí -sino más abajo del río, en el mismo lugar donde en 1650 el duque de Medinaceli proyectó levantar un puente para facilitar el paso de los ganados y cerrarlo a los barcos jerezanos (en Fig. 8).

En 1721 confluyeron las circunstancias precisas para proceder al cierre del San Pedro y comunicar su curso con el Guadalete. Después de cuatro siglos y medio desde que El Puerto de Santa María se convirtiera en un señorío, su incorporación a la

\footnotetext{
${ }^{67} \mathrm{Ya}$ apuntamos que el primer camino arrecifado entre Jerez y El Portal se construyó en 1757, al tiempo que se habilitó un nuevo muelle. B. GutiÉrREZ, Historia de Xerez de la Frontera, vol. II, 311.

68 AHMPSM, Papeles Antiguos, leg. 75, n 10. La declaración, realizada ante el corregidor, el alférez mayor y el síndico procurador mayor, se incluyó en los trámites del litigio que se mantenía con Jerez.
}

«Las intervenciones antrópicas en el curso bajo del Guadalete... » 
Corona se sospechaba próxima. Ya a mediados del XVII -en pleno litigio con Jerez a cuenta de la apertura del Guadalete al Salado - el ducado de Medinaceli se planteó en dos ocasiones revertir su posesión portuense a la monarquía. La segunda vez, proponiendo enlazar el Guadalete al Guadalquivir para convertir a El Puerto, sustituyendo al de Sanlúcar, en el puerto de embarque de los galeones de la Carrera de Indias, evitando así la peligrosa barra de Sanlúcar. Eso sí, a cambio, el ducado conservaría la Aduana. Obviamente, tal propósito no pasó de ser un proyecto irrealizable, que no sólo lo planteó El Puerto, sino también, como en otra página dijimos, Jerez. Por parte del Estado, en 1711-1712 se entablaron negociaciones con el señorío para convertirlo en ciudad realenga, pero no fructificaron; $y$ tampoco en 1727, cuando algunos vecinos elevaron un memorial a Felipe $\mathrm{V}$ con el mismo fin ${ }^{69}$. Pero el campo estaba abonado, demasiadas deudas en las arcas de los Medinaceli y muchos intereses económicos de la Corona para monopolizar en la bahía de Cádiz el tráfico de barcos comerciales con América. Finalmente, el paso se concretó el 31 de mayo de 1729, cuando el rey promulgó la incorporación.

A la gestión de don José Patiño (1667-1736) se debió la obra de 1721-1722, ocupando entonces en Cádiz el cargo de Intendente General de Marina. Como tal desarrolló una fecunda labor, fomentando el desarrollo de la Armada, la construcción naval -fundó el arsenal de La Carraca en 1732 -y el comercio marítimo. A su gestión se debió que en 1717 se trasladara a Cádiz, desde Sevilla, la Casa de la Contratación, de la que fue presidente, al tiempo que creaba un carenero en Puntales y la Real Compañía de Guardia Marinas. Ciertamente, a la labor de este eficaz y curtido político -llegaría a ser Primer Ministro en

69 J. M. GonzÁLez Beltrán, El cabildo municipal de El Puerto de Santa María (1725-1734). Un estudio de la institución en su tránsito de señorío a realengo, Jerez, 1993, 65-74. 
1734 -se debió el cierre del San Pedro, aspiración largamente esperada por El Puerto.

Para dirigir las obras sobre el terreno y su representante nombró a Gabriel de Angulo. No se ha conservado en el Archivo portuense la extensa documentación que sin duda debió generar tan colosal obra (probablemente se encuentre en Madrid o Simancas). Sí se halla, dispersa en las actas capitulares y los Papeles Antiguos, abundante documentación relacionada con la financiación de la obra. En un principio -agosto de 1721 -se acordó que Jerez costeara la mitad del gasto, y la otra mitad a tres partes: el Estado (Hacienda), El Puerto y Cádiz. Como era de esperar, se quejó Jerez, elevando al rey una exposición para que se le disminuyera su parte, lo que consiguió en junio de 1722, reduciéndose a un tercio del total del gasto. Las otras tres administraciones pagarían cada una 5.000 pesos $^{70}$. En El Puerto, la mayor parte del dinero salió de los bolsillos de 44 comerciantes en forma de préstamo (3.717 pesos), a devolver por el Ayuntamiento con intereses al $6 \%{ }^{71}$. Devolvieron los munícipes el dinero, pero con dificultad, pues en 1753 aún andaban en ello ${ }^{72}$.

70 AHMPSM, Papeles Antiguos, leg. 75, n 16 y 17.

71 La relación de los 44 comerciantes y su aportación (entre 200 y 8 pesos), J. J. IGLESIAS RODRÍGUEZ, Una ciudad mercantil en el siglo XV III, 262.

72 Así, en cabildo del 22-X, f. 174, se despachó libranza a los herederos de Timoteo O’Neale de los 25 pesos que el confiado difunto prestó en 1721.

«Las intervenciones antrópicas en el curso bajo del Guadalete...» 


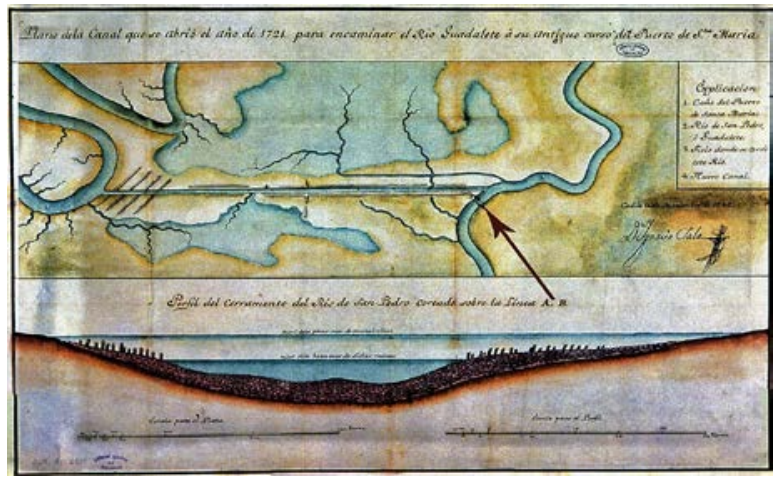

Fig. 9. Planta de la 'calle larga'y perfil del cierre del San Pedro. Ignacio Sala, copia de 1742. Archivo General de Simancas.

Las obras comenzaron en fecha imprecisa de 1721 (a fines del verano o comienzos de otoño) y concluyeron en noviembre de 1722. Consistieron en cerrar el curso del San Pedro -en el lugar desde entonces llamado La Tapa -con un lecho de piedra y estacadas, y a unos 120 metros río arriba abrir a tajo una zanja recta de 3.800 metros atravesando la marisma para enlazar con el curso del Guadalete, inmediata a éste atravesando salinas abandonadas tras la invasión angloholandesa de 1702, recién acabada la apertura del caño del Molino (Figs. 7 a 9). Las aguas del nuevo curso del Guadalete -el cauce que ha llegado a nuestros días -comenzaron a correr el 14 de noviembre de $1722^{73}$. El canal sería conocido en la época como la 'calle larga' (como continuó llamándose por los marineros portuenses hasta mediados del s. XX).

La apertura del nuevo curso del Guadalete ayudó a mejorar el estado de su barra, permitiendo el desarrollo socioeconómico y comercial que conoció El Puerto de Santa María durante el siglo XVIII con la eclosión de una activa clase

73 S. MARocho, Cosas notables ocurridas en Xerez de la Frontera desde 1647 a 1729, J. SOTO Molina (Ed.), Jerez, 1939, 34. 
mercantil nacional y extranjera que, junto a la burguesía agraria local enriquecida con la exportación de vino y aceite a América, conformaron el núcleo de una poderosa oligarquía agrariomercantil, convirtiéndose el puerto del Guadalete en uno de los más importantes de la Corona ${ }^{74}$.

\section{Los proyectos frustrados para cerrar el Guadalete y comunicarlo al San Pedro (1766-1859).}

No obstante de la obra de 1722, los problemas para salvar los bancos de arena de la boca del Guadalete continuaron, surgiendo de cuando en cuando nuevos proyectos dirigidos a solventarlos. Las nuevas iniciativas tuvieron, vistas a la larga, dos puntos comunes: todos los ingenieros y peritos enfrascados en la tarea estimaron que la única solución posible para eliminar la barra pasaba por cerrar el Guadalete y verter sus aguas al San Pedro, quedando el primero como una ría sólo alimentada por las mareas; y la segunda cuestión común es que todos los proyectos quedaron en eso, en proyectos que nunca se realizaron. Pese a ello, es de interés conocer aquellos intentos frustrados con los que se pretendió continuar moldeando el curso de los ríos, aunque la burocracia, la falta de recursos y otras dificultades no lo permitieron. De los doce proyectos que tenemos documentados -realizados entre 1766 y 1859 -destacaremos los dos más importantes ${ }^{75}$.

74 J. J. IGLESIAS MARTíNEZ, Una ciudad mercantil en el siglo XVIII.

75 J. GARCÍA DEL PALACIO, Memoria que la Comisión activa presenta a la Junta de Canalización del Guadalete, al darle cuenta de sus últimos trabajos (julio 1858), Cádiz, 1859, 26-35. Anotamos las fechas y promotores de los otros proyectos: 1766, conde de Trigona, Gobernador de El Puerto; 1768, tres estudios presentados individualmente por el brigadier Juan Manuel Porres, el marino y científico Jorge Juan y el ingeniero Francisco Haedo; 1799, bajo el patrocinio del ministro de Marina, Tomás Muñoz; 1807, capitán Gregorio Laguna; hacia 1808, marqués de Casatremañez, Gobernador de El Puerto; 1854-57-59, ingeniero Martín Recarte. Detallamos estos proyectos en J. J. LópeZ Amador y E. PÉrez FERnÁndeZ, El Puerto Gaditano de Balbo, 201-204.

«Las intervenciones antrópicas en el curso bajo del Guadalete... » 
En 1810 el capitán e ingeniero Fernando Casado de Torres, además de aconsejar la necesidad de la consabida obra, formó una extensa memoria en la que plasmó un concienzudo estudio hidrológico del Guadalete. Calculó, por ejemplo, que la arena en la línea de costa entre las desembocaduras del Guadalete y del San Pedro, en relación a la que tenía veintiún años antes según el conocido plano de la bahía de Cádiz de Vicente Tofiño había subido más de 10 pies $(2,80 \mathrm{~m})$, resultando que la línea de bajamar en 1789 era la de pleamar en 1810. Evaluó que entre ambos años se habían depositado en la boca del Guadalete 2.575 millones de varas cúbicas de arena, algo más de 8 varas $^{3}$ por cada 20 días de duro viento de levante. Este era, ciertamente, el origen del sempiterno problema de los bancos de arena de la barra del Guadalete. Si un grano hace granero, no deja de ser sorprendente cómo una partícula de arena tras otra trasladadas por los vientos reinantes, determinara el porvenir de una población, y no precisamente para bien. El mal, si no se creó, sí se incrementó a raíz de que en 1654 (el año que se cerró el Guadalete por el olivar de Cartagena) y 1655 se arrancaran, con el fin de alimentar los hornos de Cádiz, las retamas y lentiscos que poblaban las playas de Valdelagrana y de Levante. Unos años antes, entre 1632 y 1635, para fijar las dunas se plantó el primer pinar en el Coto de la Isleta de Valdelagrana, al tiempo que en 1635 también se plantó de pinos, con el mismo objetivo, los arenales de la costa frontera de Poniente, de La Puntilla a Santa Catalina; tarea que volvió a repetirse a comienzos de la década de $1650^{76}$.

En 1829, a solicitud del Ayuntamiento, una Real Orden de 4 de junio comisionó al ingeniero Pedro Delgado para realizar los estudios precisos encaminados a solucionar el imperecedero

\footnotetext{
76 AHMPSM, Act. Cap. 1635, cab. 1-X, f. 145. Act. Cap. 1650, cab. 30-VI, f. 342v. Act. Cap. 1652, cab. 19-II, f. 28. E. PÉrez FernándeZ, El Coto de la Isleta y V aldelagrana. El Puerto de Santa María. Geohistoria de un espacio entre el mar y las marismas, El Puerto, 2017, 109-113.
} 
problema de la barra. En diciembre presentó la memoria ${ }^{77}$, en la que recogió dos proyectos, acaso los más completos y complejos de los presentados en las últimas seis décadas. En el primero proponía cortar el río "por la Tapa, en donde da principio la que llaman la calle larga" para que "las aguas vuelvan a tomar su antiguo cauce y salida al mar por el Salado de San Pedro". Sugería el dragado desde el puente de San Alejandro a la boca; sustituir el incómodo muelle de madera de la Pescadería (frontero al Castillo de San Marcos) por otro de piedra; "excavar lo necesario para la formación de una dársena a fin de proporcionar desahogo al puerto, capacidad a sus fondeaderos y careneros a las embarcaciones del tráfico"; y por último:

“debe abrirse el canal espacioso y cómodo de su embarcadero de la parte interior del puerto hasta el punto de baja mar por la parte de afuera de la Bahía, y con lo que resulte de la excavación, se rellenará y terraplenará el brazo de la ría que conduce a la barra de su actual salida, que acabará de cegar el mar, formando una playa sin interrupción desde el fortín [de Santa Catalina] hasta la embocadura del San Pedro".

En el canal proyectó levantar dos muros de dos cuerpos de cantería labrada "para mantener siempre franca la comunicación con la Babia y sostener las arenas por la parte interior de la cortadura". El monto del presupuesto, 4.530 .371 reales de vellón.

En caso de que se decidiese no actuar en la barra del Guadalete, en el segundo proyecto propuso otra obra magna: excavar un canal frente al muelle de la Pescadería, atravesando el Coto de la Isleta, para darle salida al San Pedro a la altura del puente (entonces de barcas) y desembocar al mar. Estimaba que el costo de la obra, a ejecutar en un año, sería mucho más económico: un millón de reales (Fig. 10). Evidente es que ni uno ni otro proyecto se ejecutaron, por la imposibilidad de cubrir los presupuestos. Técnicamente ambos proyectos eran factibles,

77 AHMPSM, leg. 325-Canalización, 1829 nº 1.

«Las intervenciones antrópicas en el curso bajo del Guadalete... » 
como lo fue la colosal obra de 1722 del cierre del San Pedro y apertura de la 'calle larga', el curso del Guadalete actual, el que parece que desde siempre estuvo ahí.

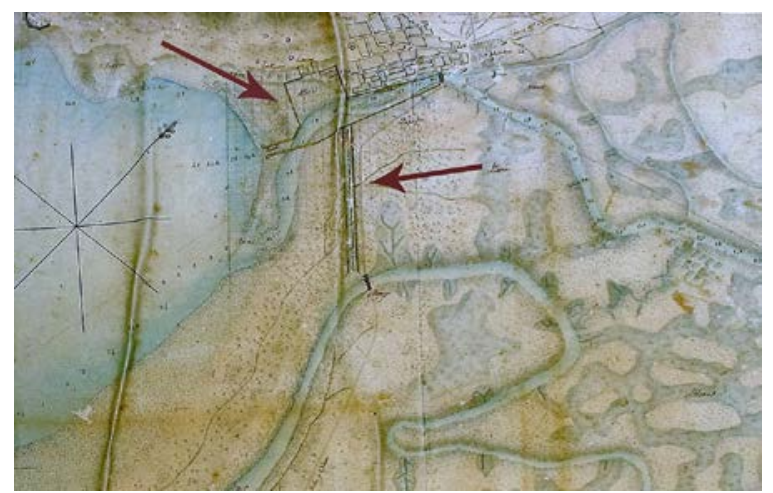

Fig. 10. Proyecto del ingeniero Pedro Delgado (1829)78.

${ }_{78}$ Marcado con flechas, la dársena que habría de construirse a las afueras de la ciudad y el canal de enlace con el San Pedro atravesando el Coto de la Isleta. Archivo Municipal de El Puerto de Santa María. 


\section{Bibliografía}

J. ABELLÁN PÉREZ, "Las barcas del Guadalete: Las relaciones entre la villa de El Puerto de Santa María y la ciudad de Jerez de la Frontera en época de los Reyes Católicos", Revista de Historia de El Puerto, 47, (2011), 9-23.

F. J. BLANCO JimÉNEZ BLANCO JIMÉNEZ, F. J., "Restos de una embarcación medieval en 'El Portal"', Boletín del Museo de Cádiz. II, (1979-1980), 77-86.

D. BRAMON, El mundo en el siglo XII. El tratado de al-Zubri, Barcelona, 1991.

A. M. CuAdrado Román, "Los canales de Jerez", Revista de Historia de Jerez, 14-15, (2008-2009), 67-90.

C. J. Dabrio, J. L. Goy, J. LARio, F. Borja, A. GonzÁlez, "The Guadalete stuary during the Holocene times (Bay of Cádiz, Spain)", INQUA MBSS Subc. Newsletter 17, (1995), 19-22.

C. J. DABRIO, J. L. GOY, C. ZAZO, "Holocene changing coastlines in the Guadalete estuary (Bay of Cádiz, Southern Spain”, Reunión Monográfica sobre el cambio de la costa. Los sistemas de Rías. (1995), 45-50.

E. DE LOS Ríos MARTíneZ, "Los informes de Cristóbal de Rojas y Julio César Fontana para hacer un muelle y un puente sobre el río Guadalete en Jerez de la Frontera", Laboratorio de Arte, 14, (2001), 1325.

T. FALCÓn, “Arquitectura barroca en Jerez”. Centro de Estudios Históricos Jerezanos, Jerez, (1993).

J. FERRER ANDRADE, "La pesca del sábalo en el río Guadalete", Revista de Historia de El Puerto, 14, 1995), 23-61.

J. GARCÍA DEL PALACIO, Memoria que la Comisión activa presenta a la Junta de Canalización del Guadalete, al darle cuenta de sus últimos trabajos (julio 1858). Cádiz, 1859.

N. GARCÍA TAPIA, Ingeniería y Arquitectura en el Renacimiento español, Valladolid, 1990.

J. GAVAla y LABORDE (1959), La geología de la costa y Babia de Cádizy el poema «Ora Marítima» de Avieno. Madrid, Instituto Geológico y Minero de España, Cádiz, 1992.

M. GonZÁlez JiméneZ, "El Puerto de Santa María en tiempos de Alfonso X el Sabio", Nuestros orígenes históricos como El Puerto de Santa María, El Puerto de Santa María, 1988. 
J. M. GonzÁlez Beltrán, El cabildo municipal de El Puerto de Santa María (1725-1734). Un estudio de la institución en su tránsito de señorio a realengo, Jerez, 1993.

M. Ma GONZÁLEZ GORDON, Jerez-Xerez-Scheris, Jerez, 1935.

J. GonzÁlez Moreno, El condado del Puerto de Santa María, Cádiz, 1989.

R. González Rodríguez, L. Aguilar Moya, D. Martín Mochales, F. Barrionuevo Contreras, M. Collado Moreno, (Carta Arqueológica Municipal de Jerez: 1: El núcleo urbano. Junta de Andalucía-Arqueología Monografías, s. a.

F. J. Gracia, C. Alonso, M. Gallardo, F. Giles, J. Benavente y F. LÓPEZ AgUAYO, "Evolución eustática postflandriense en las marismas del Sur de la Bahía de Cádiz", Geogaceta, 27, (2000), 71-74.

B. GutiÉRrez (1757), Historia de Xerez de la Frontera, Jerez, 1989.

A. Hidalgo OrTega, Noticias sobre el proyecto de hacer puerto a Jerez, Jerez, 1881.

J. J. IGLESIAS RODRígUEZ, Una ciudad mercantil en el siglo XVIII: El Puerto de Santa María, Sevilla, 1991.

R. KaGAN, Ciudades del Siglo de Oro. Las vistas españolas de Anton van den Wyngaerde, Madrid, 2008.

J. LARIO GÓMEZ, Último y presente interglacial en el área de conexión Atlántico-Mediterráneo (Sur de España). Variaciones del nivel del mar, paleoclima y paleoambientes, Tesis Doctoral Inédita, Universidad Complutense de Madrid, 1996.

J. J. López Amador y E. Pérez Fernández, El Puerto Gaditano de Balbo. El Puerto de Santa María, Cádiz, El Puerto, 2013.

M. LÓPEZ MuÑoz, Las trovas del Guadalete, El Puerto, 1926.

J. Machimbarrena AguirrebengoA, "Las comunicaciones terrestres del Puerto de Cádiz", Revista de Obras Públicas, 2807, (1949), 97-104.

S. MArocho, Cosas notables ocurridas en Xerez de la Frontera desde 1647 a 1729. Ed. J. Soto Molina, Jerez, 1939.

L. MÁrquez Carmona, "El molino mareal del caño de El Puerto de Santa María", Revista de Historia de El Puerto, 40, (2008), 81-102.

E. MARTÍN GUTIÉRREZ, La organización del paisaje rural durante la Baja Edad Media. El ejemplo de Jerez de la Frontera, Sevilla, 2004. 
E. Martín GutiérRez, "La época cristiana (1264-1492)", D. CARO CANCELA (Coord.), Historia de Jerez de la Frontera, t. I: De los orígenes a la época medieval, Cádiz, 1999.

J. Montoya Martínez, "Cancionero de Santa María de El Puerto. Edición, Traducción y Notas", Alcanate I (1998-1999).

A. MuÑoz GÓmeZ, Dos documentos curiosos de los siglos XV y XVI. Convenio entre Jerezy los pescadores de San Vicente de la Barquera, Jerez, 1892.

A. MuÑoz GómeZ, Más documentos inéditos de los siglos XV y XVI. La pesquería de Puerto Franco, Jerez, 1892.

E. PÉrez FERnÁndEZ, "Por orden del Duque mi señor...", Pliegos de la Academia Bellas Artes Santa Cecilia, 5, (1992), 20-22.

E. PÉrez FernándeZ, El Coto de la Isleta y Valdelagrana. El Puerto de Santa María. Geohistoria de un espacio entre el mar y las marismas, El Puerto, 2017.

E. Pérez Fernández, J. J. López Amador, J. A. Ruiz Gil, "Arqueología histórica de los siglos XV-XVI en El Puerto de Santa María", Actas del Congreso 'El Puerto, su entorno y América', 14-16 octubre 1992. El Puerto de Santa María, 1994.

J. PORTILlo, Noches jerezanas, o sea la historia y descripción de la M. N. y M. L. Ciudad de Jerez de la Frontera y su término, Jerez, 1839.

E. RALLÓN, Historia de Xerez de la Frontera y de los Reyes que la dominaron desde su primera fundación, Ed. A. MARÍN Y E. MARTÍN, Cádiz, 1997.

R. Romero Medina Y M. Romero Bejarano, "Arquitectura tardogótica en el sur del antiguo Arzobispado de Sevilla: los maestros canteros y la construcción del puente de Cartuja (1525-1541)", Boletín del Museo e Instituto Camón Ažar, 106, (2010), 251-288.

C. SÁnCHez Albornoz, Otra vez. Guadalete y Covadonga, Buenos Aires, 1944.

H. SANCHO DE Sopranis, Historia del Puerto de Santa María desde su incorporación a los dominios cristianos en 1259 hasta el año mil ochocientos, Cádiz, 1943.

H. SANChO DE SOPRANIS y J. DE la LASTRA, Historia de Jerez de la Frontera desde su incorporación a los dominios cristianos, Jerez, 1965.

D. SuÁreZ QueVEDO, "Navegación fluvial e ingeniería militar en España, siglos XVI-XVII. De Pérez de Oliva y Antonelli, a Leonardo Torriani y Luis Carducha", Anales de Historia del Arte, 17, (2007), 117 153.

«Las intervenciones antrópicas en el curso bajo del Guadalete... » 